\title{
Assessing Commuting Energy and Emissions Savings through Remote Working and Carpooling: Lessons from an Italian Region
}

\author{
Michel Noussan *(D) and Matteo Jarre (DD
}

Citation: Noussan, M.; Jarre, M. Assessing Commuting Energy and Emissions Savings through Remote Working and Carpooling: Lessons from an Italian Region. Energies 2021, 14, 7177. https://doi.org/10.3390/ en14217177

Academic Editors: Kun Mo Lee and Victor Manuel Ferreira Moutinho

Received: 27 July 2021

Accepted: 27 October 2021

Published: 1 November 2021

Publisher's Note: MDPI stays neutral with regard to jurisdictional claims in published maps and institutional affiliations.

Copyright: (c) 2021 by the authors. Licensee MDPI, Basel, Switzerland. This article is an open access article distributed under the terms and conditions of the Creative Commons Attribution (CC BY) license (https:/ / creativecommons.org/licenses/by/ $4.0 /)$.
Decisio BV, Valkenburgerstraat 212, 1011 ND Amsterdam, The Netherlands; m.jarre@decisio.nl

* Correspondence: m.noussan@decisio.nl

\begin{abstract}
Effective solutions are needed to decrease the greenhouse gases emissions of the transport sector, not only in terms of supply-side measures, but also including demand-side solutions. This paper focuses on the passenger demand related to daily commuting, either for work or study purposes. A bottom-up analysis is presented, which draws from detailed data for Lombardy, the most populous region in Northern Italy, to build an estimate of the annual energy consumption and emissions related to commuting. The potential of different measures to decrease emissions is evaluated, including the renovation of the vehicle stock, higher levels of remote working, and the deployment of carpooling schemes. The results show that the largest part of the current emissions from commuting is caused by car use, both due to its higher modal share and to the higher specific emissions, which are in turn also contributed by the low occupancy rates. The renewal of the current vehicle stock can lead to significant emission savings, thanks to both improved efficiency and higher shares of electrification. Remote working could also play a significant part, especially when it is applied to workers that face the longest commuting distances. Conversely, carpooling seems to be providing lower benefits, not so much because of lower effectiveness but more so because of constraints and barriers to its implementation.
\end{abstract}

Keywords: transport; commuting; energy; emissions; remote working; carpooling

\section{Introduction}

The greenhouse gas (GHG) emissions of the transport sector are hard to abate, and in different world regions they have increased at a higher pace than in other sectors. Energy consumption in transportation still heavily relies on fossil fuels, with oil products accounting for more than $90 \%$ of the global final energy consumption of the sector [1]. In the European Union, transport emissions have continued to rise, despite a large body of regulation that has limited the emission intensity of new vehicles. Global transport emissions are also expected to rise steadily in future scenarios [2]. To reach the challenging decarbonization targets ahead, effective strategies in the transport sector need to focus on multiple measures, including a decrease of mobility demand, a modal shift towards collective and active transport modes, an improved energy efficiency of new vehicles, higher load factors, and the use of low-carbon technologies.

The transport sector includes a wide range of applications, both in passenger and freight transport, and specific measures are needed to address the characteristics of each transport segment. Additionally, passenger demand is driven by multiple purposes, including work and study commuting, family organization, and leisure among the others. Of those, daily commuting represents an important share of total trips, and it is generally responsible for significant impacts in terms of emissions and congestion, especially in morning and evening peak hours.

The issue of energy consumption and GHG emissions of commuting has been addressed in the academic literature by considering different aspects and spatial and geo- 
graphic contexts. Kissinger and Reznik [3] estimated commute-related GHG emissions from private vehicles used by the city of Tel Aviv-Jaffa (Israel) by considering specific routes and comparing technological, behavioral, and policy changes to support emissions savings. An analysis in the Liege province, in Belgium, highlights that the daily mobility of inhabitants has a significant effect on $\mathrm{CO}_{2}$ emission and energy consumption in the city [4]. The research highlights the higher contribution of working days, and the importance of implementing long-term measures that support a shift towards more sustainable transport modes, including public transport and active mobility. Wei and Pan [5] consider the distribution of commuting emissions across workers in Shanghai, highlighting that almost $80 \%$ of emissions are from top $20 \%$ respondents. Other studies consider the evaluation of commuting impacts in the framework of the calculation of the total emissions caused by the operation of specific buildings [6]. Other studies are also considering the impacts associated to the material needed to build the transport infrastructure and the vehicles supporting urban mobility to reach more comprehensive results [7].

Results from analyses of commuting patterns can be useful also for other applications. Driving habits, especially when considering the daily routine, are a crucial aspect in studying the potential of different decarbonization strategies, including the deployment of EVs [8]. Regular trips are used to estimate the best strategy to allocate charging needs in different time slots over the day, as well as defining battery charging constraints in optimization tools. Those analysis also exploit the real-world driving data of (current or potential) EV drivers, to increase the reliability in estimating the daily routine activity of users [9]. An optimal deployment of EVs, especially when coupled with vehicle-to-grid configuration, can help in exploiting the local excess of RES generation, especially from residential [10] and workplace [11] PV systems. Conversely, uncontrolled charging can lead to significant impacts on the power network, in terms of energy consumption and peak power demand [12]. In addition, a wide adoption of EVs will need to be supported by a proper charging infrastructure [13], which may prove to be critical especially in dense urban areas. Different papers are proposing a range of tools to support the planning and deployment of public charging infrastructure, including multi-criteria decision processes [14], artificial neural networks [15] and multi-commodity flow problem algorithms [16].

A proper assessment of commuting patterns is also a necessary step to develop specific strategies to decrease commuting emissions. Among the most promising measures to decrease the environmental impact of commuting, in addition to modal shift towards public and active transportation, which are widely discussed in the literature [17], two additional measures are carpooling and remote working. The current pandemic may shift the preference of users towards the latter, as the former may see a decreasing trend, especially in the short run, due to potential problems related to social distancing. Still, regular carpooling with office colleagues may prove to be an effective way to reduce the number of human interactions with strangers when compared to public transport. Nevertheless, in the long run an optimized use of cars is of utmost importance in improving the energy efficiency of the transport sector, especially in commuting trips. Such optimization is in fact among the main targets of the introduction of self-driving vehicles, although specific measures are needed to ensure a positive effect [18].

Remote working represents an interesting option to reduce mobility demand. It is gaining momentum after the COVID-19 lockdowns in several countries pushed workers and companies to adopt such scheme. The potential effects of remote working on energy consumption have been discussed in the literature. A comprehensive analysis on the energy and climate impacts of remote working is carried out in [19]. The authors conclude that the majority of the studies they have considered highlight that remote working can reduce energy use, but some works suggest that remote working actually increases, or has a neutral impact, on energy use. Differences in the methodology and assumptions of the available studies make it difficult to estimate average energy savings indicators. In addition, some works suggest also that remote working may lead to unpredictable increases in non-work travel and home energy consumption that may outweigh the benefits from 
reduced commuting [20,21]. In addition the direct and indirect impacts of information and communication technologies should be taken into account when evaluating the broader implications of remote working [22].

Carpooling has been often seen as an effective strategy to decrease private transport emissions, thanks to the increase of average vehicle occupancy, but also by decreasing time spent in congestion during peak hours, provided that carpooling penetration reaches an acceptable level. Increasing vehicle occupancy can play a significant role in the decarbonization of passenger transport [23]. Still, the flexibility provided by private cars is strongly limited in case of carpooling, and this aspect remains a major barrier that often hinder carpooling deployment. Furthermore, cultural barriers are pushing many users to avoid sharing trips with strangers [24]. Plus, the relatively low perceived cost of car ownership in most developed countries is limiting the organization of informal carpooling activities. A survey developed in France in 2019 highlighted that individuals traveling as carpool passenger incur a "discomfort" cost of on average 4.5 euros per extra passenger in the same vehicle [25].

Digital technologies are becoming an important tool to help matching the demand and supply of shared trips, and some companies are specifically targeting commuting. Successful business models are based on creating value from the shared trips by calculating energy savings that can be used to fulfill specific regulation targets. This business model has been applied in Italy by the startup Jojob [26] in 2015, through partnerships with large scale companies to provide carpooling options to their workers based on commuting trips. The energy savings were then sold to those companies to meet their national regulation targets on energy efficiency. Digitalization is also being used to quantify the potential benefits of carpooling, thanks to the possibility of studying vehicle trajectory data from difference sources. An analysis on license plate recognition data for a Chinese city highlighted interesting results [27], with a decrease of trip volumes in the range $32-49 \%$ depending on different penetration levels, with peak-hour travel speeds on most road segments increasing by $5-40 \%$. Another option includes the possibility of exploiting operational data from carpooling providers. A case study in Beijing [28] highlighted the significant carpooling potential in providing a feeder service for public transport, by effectively aggregating commuters mobility in suburban areas. While these works provide interesting insights on the potential in specific cases, assessments of the potential contribution of carpooling are seldom seen in the literature.

This paper aims at improving the literature gap by addressing two specific goals: The first is to provide a detailed assessment of the current characteristics of daily trips, together with their energy consumption and GHG emissions, exploiting a large database of survey data from Lombardy. The second goal is to build on these results to assess the potential energy and emissions savings that could stem from increased levels of remote working and carpooling under different assumptions.

The bottom-up approach allows considering multiple aspects of interest, including trips and passenger-km distributions across modes and commuting distances. In addition, the calculated GHG emissions are compared to the potential benefits of upgrading the vehicle stock, and implementing different levels of remote working and carpooling.

The analysis of this Italian region is representative for many other regions and countries, as daily trips characteristics show similar patterns, although with some differences in modal shares. Such results can present useful insights for countries with a similar cultural and economic context, and may also shed light upon possible future pathways for countries that are currently seeing lower motorization rates and commuting demand.

\section{Methods}

\subsection{Analysis of Commuting Demand}

The commuting demand has been calculated by means of a bottom-up analysis based on an origin-destination (OD) matrix of all the daily trips available for Lombardy. The total 
commuting demand and the energy consumption and GHG emissions have been calculated based on the distance and on the modal share of commuters.

Lombardy, located in Northern Italy, is one of the largest Italian regions, with a population of 10 million inhabitants, approximately one-sixth of the total population in the country. A map of the region, together with its 12 provinces, is reported in Figure 1. Lombardy is divided into 1506 municipalities, of which almost 200 are larger than 10,000 inhabitants and 320 have less than 1000 inhabitants. The motorization rate is around 620 cars per 1000 inhabitants, slightly lower than the national average. This rate shows some variation across provinces.

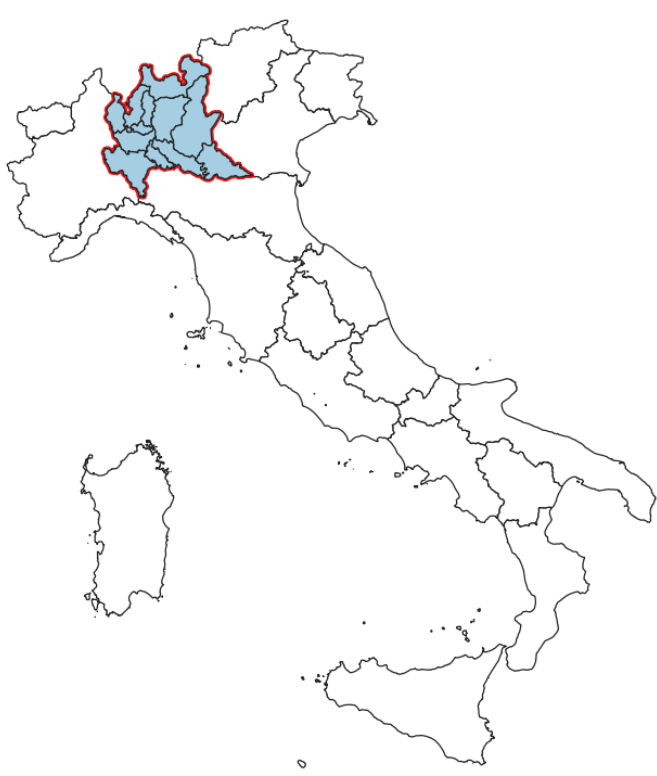

Figure 1. Map of Lombardy, highlighted in red, and its 12 provinces, colored in light blue.

The OD matrix that has been used is published by Regione Lombardia [29], and it is based on a range of sources, including surveys, a national census, and the contribution of local authorities and other stakeholders. The first matrix has been published in 2015, and data have then been updated for 2016 and for 2020. The latest version is the one that we have used in this study. The OD matrix includes data on a total of around 17 million trips for any typical working day, both in the same municipality or in other municipalities. Available data include

- municipalities of origin and destination, purpose of the travel (work, study, business, leisure, return trips);

- main transport mode that is used (car as driver, car as passenger, motorbike, bus, rail, bike, foot, other); and

- hour of travel beginning.

The OD matrix includes a total of 1450 zones, where each zone represents a municipality, with some exceptions. The largest cities are divided into multiple zones (the municipality of Milan includes 20 zones), while very small municipalities are aggregated in a single zone.

These data have been integrated with additional sources of information to calculate the travel distances, which have been used in this study to compute the passenger-km $(\mathrm{pkm})$ figures. In particular, to calculate the commuting distance between different municipalities, the default method would be to calculate the direct distance (i.e., as the crow flies) between the georeferenced center of the two municipalities, which leads to a significant approximation. A more detailed approach has been chosen by exploiting the available data on the actual road distance for any pairing of municipalities in Italy [30]. This dataset includes the actual road distances calculated with a professional geographic information 
system (GIS) database of road infrastructure which have been applied to calculate the distance of all the trips between two different municipalities. While road trips represent the majority of inter-urban trips, this choice leads to an approximation of distance for train connections, which are often shorter and closer to the as the crow flies distance than road trips. Still, for the sake of simplicity and due to the lack of data, the same approach has been used also for train commuting. The median ratio between actual road distance and the distance as the crow flies we computed for Lombardy is $\sim 1.3$, which is very similar to the results from the same calculation at the national level.

A different approach has been used to consider the trips within the same municipality, for which the previously described approach could not be applied, as any trip starts and ends in the same georeferenced center of the same municipality, thus yielding a (wrong) distance equal to zero. The distances have thus been estimated by considering an average equivalent distance within the municipality, calculated as the radius of a circle with the same surface of the municipality. This distance has then been corrected by the coefficient 1.3 described in the previous paragraph to estimate the average road distance traveled by commuters.

\subsection{Calculation of Passenger Transport Impacts}

The available information on mobility demand is used to estimate the energy consumption of transportation during a typical working day, as well as the direct and the well-to-wheels (WTW) emissions. The calculation is based on average consumption data and emission factors, obtained by the most updated literature on the subject [31,32]. As cars represent the main transport mode, a more detailed analysis has been performed based on the data on the actual fleet of Italian cars, divided by fuel and technology [33].

The information that has been used for estimating fuel consumption for the current technologies available in Italy for private cars is reported in Table 1. The data on fuel consumption, which are based on [31], have been coupled with the WTW emission factors of Table 2 to calculate the total amount of GHG emissions of private cars. The data refer to the average information for the car fleet, while significant variations exist based on car age, car segment, type of driving conditions, etc. However, considering this additional variability goes beyond the scope of this work, which is based on average data for the entire fleet.

Table 1. Average cars energy consumption per technology and fuel. ICE: internal combustion engine, HEV: hybrid electric vehicle, PHEV: plug-in hybrid electric vehicle, BEV: battery electric vehicle, LPG: liquefied petroleum gas, CNG: compressed natural gas. Source: [31].

\begin{tabular}{lrr}
\hline Technologies & \multicolumn{2}{c}{ Fuel Consumption $\mathbf{( k W h} / \mathbf{1 0 0} \mathbf{~ k m})$} \\
\hline & current $(2015)$ & future $(2025+)$ \\
ICE-Gasoline & 48.1 & 39.1 \\
ICE-Diesel & 40.4 & 36.0 \\
ICE-LPG & 49.1 & 39.3 \\
ICE-CNG & 48.9 & 38.5 \\
HEV-Gasoline & 35.5 & 28.5 \\
HEV-Diesel & 32.1 & 30.0 \\
PHEV-Gasoline (gasoline) & 12.1 & 2.5 \\
PHEV-Gasoline (electricity) & 10.3 & 13.8 \\
BEV & 12.7 & 11.9 \\
\hline
\end{tabular}


Table 2. Emission factors expressed in gCO2eq $/ \mathrm{kWh}$ for well-to-tank (WTT), tank-to-wheels (TTW), and well-to-wheels (WTW) analyses for different fuels. Source: [32].

\begin{tabular}{lrrr}
\hline Fuel & WTT & TTW & WTW \\
\hline Diesel & 68.0 & 263.5 & 331.6 \\
Gasoline & 61.2 & 264.2 & 325.4 \\
CNG & 54.4 & 202.3 & 256.7 \\
LPG & 28.1 & 236.5 & 264.6 \\
Biomethane & 34.2 & 0.0 & 34.2 \\
Ethanol (EU mix) & 187.2 & 0.0 & 187.2 \\
Biodiesel (EU mix) & 133.2 & 0.0 & 133.2 \\
Electricity (IT mix-2019) & 276.3 & 0.0 & 276.3 \\
Electricity (IT-mix 2030) & 193.4 & 0.0 & 193.4 \\
\hline
\end{tabular}

At the same time, these average factors may be a little too optimistic when compared with other studies on the existing fleet, such as in [34]. However, these values have been selected for consistency with current literature and the possibility of using the same source for all the available technologies. Moreover, the adopted emission factors shape the institutional ground for any transport emission-related policy in the whole EU and shall thus be taken as reference for any comparison.

In addition, note that data for plug-in hybrid electric vehicles (PHEV) include both the consumption of gasoline and electricity, depending on their usage, and the share of those fuels may considerably vary depending on the drivers behaviour and the available power charging infrastructure. This also explains the large variation from the current to the future figures for energy consumption of PHEVs in Table 1.

The calculation of the impacts related to private cars are based on the actual car stock for 2019 and the estimated future car stock, as reported in Table 3. These numbers represent the total number of vehicles per each technology, and they are used to compute an average figure for the impact of car commuting. The future vehicle stock has been estimated by considering the historical trend and the national targets on EV deployment by 2030. It is important to remember that the actual distribution of car ownership may vary across commuters, in particular considering the average annual distance of cars. Car users with higher annual mileage are usually choosing diesel cars, which show lower total costs of ownership, albeit higher investment costs. This is due both to the higher efficiency of diesel engines and to the lower cost of diesel in Italy when compared to gasoline, mostly due to lower taxes.

Table 3. Italian car stock by technology. Current data based on data from in [33]; future data based on author's estimation considering historical trend and national targets. The vkm-weighted shares are based on annual mileage data from in [34].

\begin{tabular}{lrrrr}
\hline Technologies & \multicolumn{2}{c}{ Vehicle Stock Share } & \multicolumn{2}{c}{ Vkm-Weighted Share } \\
\hline & current $(2019)$ & future $(2030)$ & current $(2019)$ & future $(2030)$ \\
ICE-gasoline & $46.0 \%$ & $32.4 \%$ & $31.4 \%$ & $20.3 \%$ \\
ICE-diesel & $44.2 \%$ & $35.1 \%$ & $56.6 \%$ & $48.4 \%$ \\
ICE-LPG & $6.5 \%$ & $6.8 \%$ & $8.3 \%$ & $9.3 \%$ \\
ICE-CNG & $2.4 \%$ & $5.4 \%$ & $3.1 \%$ & $7.4 \%$ \\
HEV-Gasoline & $0.8 \%$ & $2.7 \%$ & $0.5 \%$ & $1.7 \%$ \\
HEV-Diesel & $0.0 \%$ & $1.4 \%$ & $0.0 \%$ & $1.9 \%$ \\
PHEV-Gasoline & $0.0 \%$ & $5.4 \%$ & $0.0 \%$ & $3.7 \%$ \\
BEV & $0.1 \%$ & $10.8 \%$ & $0.1 \%$ & $7.3 \%$ \\
\hline
\end{tabular}

For this reason, the vehicle stock share has been corrected by weighting if for the actual $\mathrm{vkm}$ driven for every technology, based on current data and future estimates provided in [34] for diesel and gasoline cars. The current annual car usage that is reported, based on statistical data, is $7400 \mathrm{~km}$ for gasoline cars and 13,900 km for diesel cars. These values 
are projected to 6800 and 15,000 km, respectively, by 2030 [34]. Unfortunately, these data are based on total car usage, and no specific information is available for commuting. Thus, a slightly different distribution of car ownership (and mileage) may apply to commuters, which cannot be estimated with the available data. Due to the lack of data on annual mileage for other technologies, natural gas and liquefied petroleum gas (LPG) cars have been considered similar to diesel, as they are mostly used by people with higher annual mileage. On the other hand, electric cars have been considered more similar to gasoline cars, as they are mostly used for urban trips and low distances. The results of this calculation lead to slightly different shares, as reported in the right columns of Table 3.

These values have been used to calculate the average impact of car trips, as they are closer to the reality, although they are based on the total number of citizens trips, not only on those related to commuting. For this reason, as diesel cars are used in applications that involve long annual distances (e.g., salesmen, drivers, etc.), their contribution could be slightly overestimated. Still, diesel cars can also be attractive for commuters for the very same reason. Taking into account these two competing trends, we believe that this approach is more suitable to estimate a realistic impact of commuting by car.

The average energy consumption for the other transport modes has been estimated by considering average specific values from literature based on passenger- $\mathrm{km}$ [35], which have been calculated by considering the fuel mix of the current Italian fleet for buses and trains. A 10\% decrease in energy consumption has been estimated for future vehicles based on internal combustion engine (ICE) technology, while a 5\% decrease has been allocated to electric public transport, for which the margins of improvement appear narrower in terms of pure energy consumption (and not in terms of emissions).

The calculation of the energy consumption forms the basis for the estimation of GHG emissions, which are obtained by applying relevant emission factors for transport fuels and electricity, as reported in Table 2. Data on fuels emissions are based on European supply chains, which are in line with Italian values. Conversely, the emission factor for electricity has been calculated specifically for Italy [36], as national electricity mixes show significant variations from a country to another.

The tablereports different emission factors, based on the phases of the supply chain that are considered: well-to-tank (WTT), tank-to-wheels (TTW), and well-to-wheels (WTW). Still, the results of this work will be focused on WTW emissions, which allow including all the impacts caused by passenger transport, instead of limiting the focus to direct tailpipe emissions. In accordance with the usual approach in the literature, biofuels are considered as carbon-neutral, and thus their tailpipe emissions are set to zero, under the assumption that those emissions are compensated by those captured during the growth of the crops that are used for biofuel production.

The calculation of the total GHG emissions, considering a WTW perspective, is thus represented by the following equation:

$$
E_{W T W}=\sum_{m=1}^{n} D_{m} \cdot \sum_{e=1}^{p} S_{e} \cdot F_{e} \cdot E F_{e}
$$

where $E_{W T W}$ are the total emissions in $\mathrm{kg}, D_{m}$ is the passenger demand for each mode in $\mathrm{pkm}, S_{e}$ is the share of each energy carrier for each mode, $F_{e}$ is the specific fuel consumption per each energy carrier in $\mathrm{kWh} / \mathrm{pkm}$, and $E F_{e}$ is the WTW emission factor for each energy carrier, expressed in $\mathrm{kg}_{\mathrm{CO} 2 \mathrm{eq}} / \mathrm{kWh}$, as reported in Table 2.

\subsection{Remote Working and Carpooling}

In addition to the quantification of the current commuting impacts in terms of GHG emissions, as well as the effect of a vehicle stock renewal in the next decade, this paper aims at evaluating the potential effect of different penetration levels of remote working and carpooling. For the sake of simplicity, such policies have been applied to work-only trips, whereas study trips have been neglected, the rationale being that remote studying 
has proven to be much more contentious and hardly "permanent" than remote working during the COVID-19 lockdowns.

\subsubsection{Remote Working}

To account for the additional benefits of fostering an increase of remote working, four different strategies have been compared: (1) an even distribution of remote working across commuters, (2) an even distribution of remote working on people that commute by car, (3) a gradual distribution starting from the people with higher commuting distances, and (4) a gradual distribution starting from people moving with private cars and higher commuting distances.

The annual effects are calculated by considering three days of remote working per week, to account for the need of office activities as well as the preferences of workers that seldom want a total isolation from the working place. The total share of remote workers has been considered up to $10 \%$, to account for the fact that several activities cannot be performed remotely, as well as to provide a reasonable range of penetration.

Moreover, it is important to note that strategies (3) and (4) are based on the assumption that all the longer trips can be effectively switched to remote working scheme, which may not be the case in the real world. Thus, these two scenarios represent the most positive effects that could be achieved given the described assumptions, but in practice they may be out of reach.

\subsubsection{Carpooling}

In comparison with remote working, an effective analysis of the carpooling potential needs to take into account additional factors. Actual figures on low penetration rates, even in countries that adopted dedicated policies to foster carpooling, reflect the practical difficulties in sharing daily commuting trips. Such barriers include slightly different origins and destinations, the time of the commuting (especially for the return trip), the need to include other activities in the return trip (e.g., running errands), or the real or perceived (in)flexibility in changing trip programs and schedule.

To account for these barriers, with the information that is available in the OD matrix, some specific hypotheses have been considered. Only car trips with the same origin and the same destination have been considered suitable, i.e., no carpooling involving a partial sharing of the trip has been evaluated. To limit the potential issues related to different origins and destinations within each municipality, the potential carpooling penetration has been limited to routes (i.e., origin-destination couples) with more than 50 people traveling by car (considering only the outward journeys). Such routes represent only $4 \%$ of the total routes by car, but they account for $59 \%$ of total trips by car and $31 \%$ of total pkm by car, highlighting how few routes are actually the significant ones, at least in terms of usage. We have also performed a check to ensure that the bulk of these trips happen in the very same hours, so that carpooling can represent a viable option.

Moreover, a maximum carpooling share of $20 \%$ has been set. This is defined as the number of drivers that become passengers, each leading to the removal of a car trip. Such $20 \%$ share is applied to the routes selection previously described, thus leading to an overall share of displaced trips lower than $20 \%$ (when considered on the total number of routes). These figures thus highlight that the penetration potential of carpooling is expected to be lower than the one of remote working.

\section{Results}

\subsection{Commuting Mobility Demand}

The analysis of the detailed OD matrix illustrates different elements of the characteristics of daily trips in Lombardy.

Figure 2 represents the modal share of daily commuting, both on a trip perspective (figure A) and on a pkm perspective (figure B). The chart also highlights the distribution of trips per class of distance, showing that, in accordance with other studies (see, e.g., 
in [37-39] among others), more than $40 \%$ of the trips are shorter than $5 \mathrm{~km}$, but the bulk of pkm is represented by trips between 5 and $50 \mathrm{~km}$. Considering the modal shares, which are calculated on a regional basis, car is always the preferred mode, with a noticeable contribution of active modes for short trips (up to $5 \mathrm{~km}$ ) and of rail in long trips (more than $20 \mathrm{~km})$.
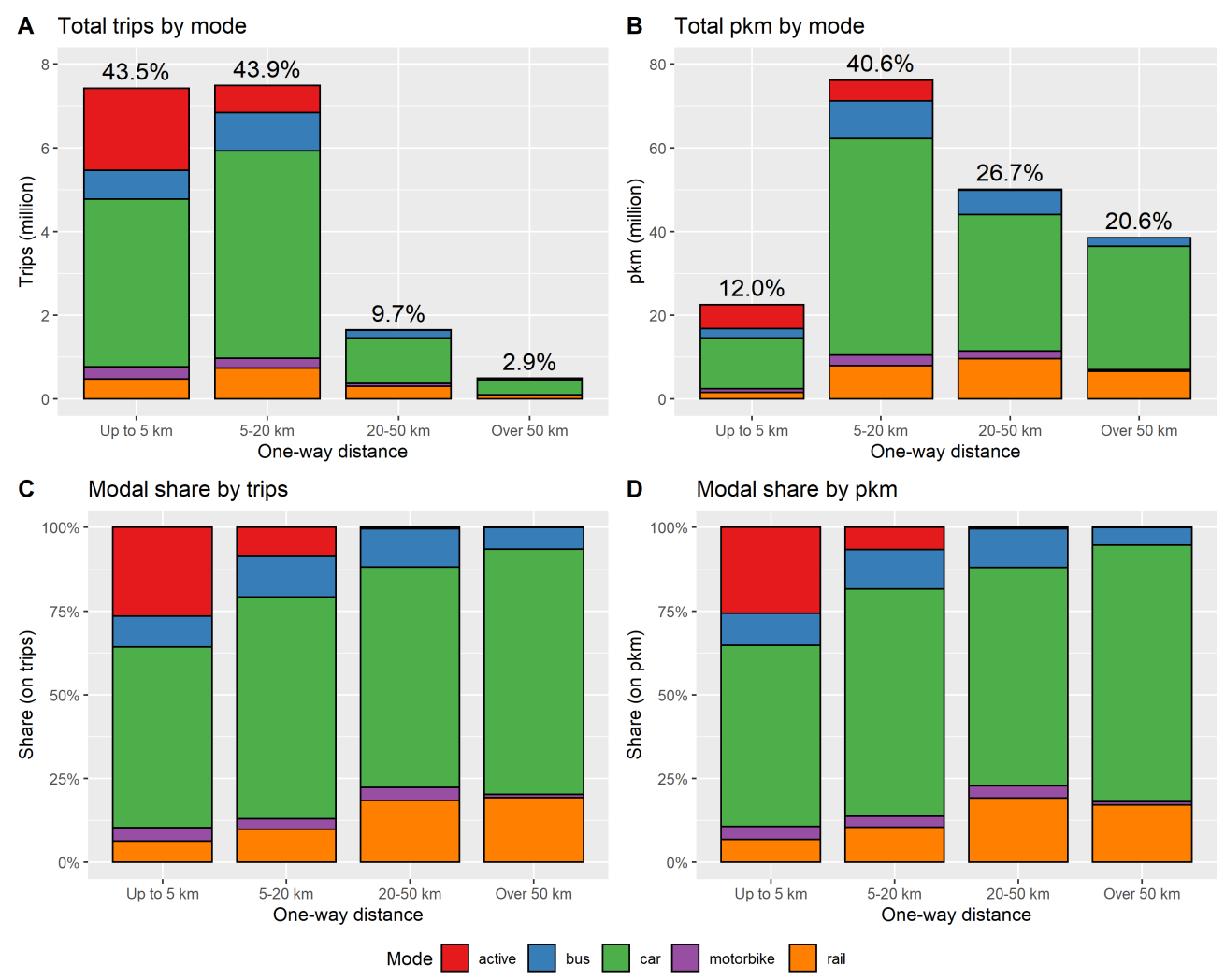

Figure 2. Statistics on daily trips by mode in Lombardy. Total trips by mode (A), total pkm by mode (B), modal share by trips (C), and modal share by pkm (D).

These trips include all the trips that are done over a typical day in Lombardy (excluding the trips outside the region, which are less than $7 \%$ of the total in the OD matrix), and account for 187 million pkm in total. Considering the purpose of the trip, one-third of daily pkm is for commuting ( $26.5 \%$ for work and $6.5 \%$ for study), $19 \%$ is for occasional trips, $2 \%$ for business trips, and the remaining $46 \%$ of $\mathrm{pkm}$ is due to the return trips. Note that the modal share of car, which sums up to $68 \%$ of total pkms, varies significantly depending the purpose of the trip: while it reaches $75 \%$ for work commuting and $65 \%$ for occasional trips, it remains at $37 \%$ for school commuting (of which two thirds of pkm represented by car passengers not driving). This last aspect may be slightly affected by some specific trips in which a parent driving to work may bring his child to school in the very same trip, which then counts for two different purposes and is seen as two separate trips. For this reason, it is not correct to calculate the average car occupancy for educational trips only, since it could lead to wrong conclusions. Still, putting together all the trips, the average number of car occupants for commuting trips is $~ 1.16$ when calculated on total commuting $\mathrm{pkm}$, but as low as 1.08 when considering only work-related pkm. These figures are in line with similar values calculated at the national level, as well as for other countries (see, for example, the already-mentioned works in $[37,39]$ among others).

Another interesting result is the cumulative representation of commuting trips by distance, reported in Figure 3. The left panel represents the cumulative share by number of trips, while in the right one the computation is based on the total pkm. 


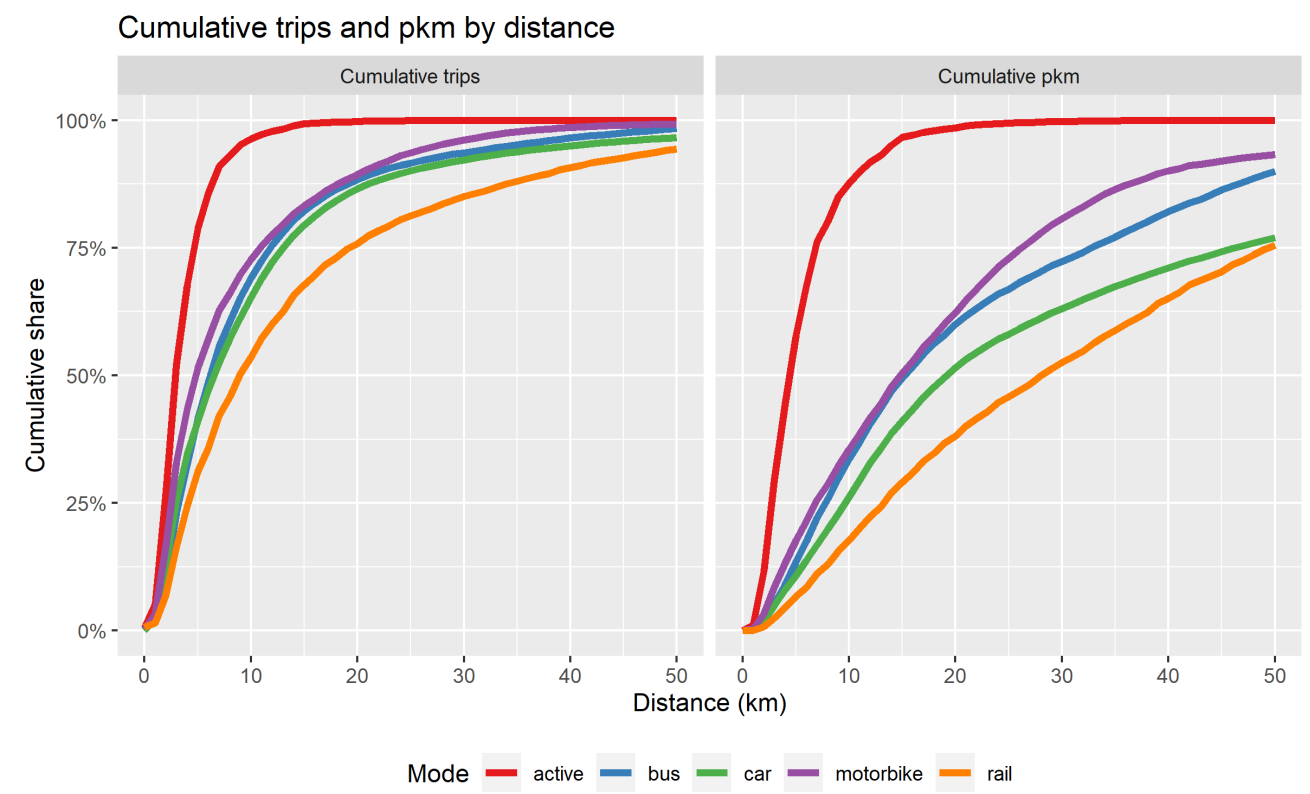

Figure 3. Cumulative commuting trips in Lombardy, by \% of trips, and by \% of passenger $\mathrm{km}$ (pkm).

The charts highlight the uneven distribution of transport modes by distance, which is in line with similar representations for other countries [40]. While active modes are naturally more frequent on short distances, the opposite is true for rail (which includes train, trams, and metro). As already represented in Figure 2, approximately one-quarter of the pkm for both cars and rail is due to trips longer than $50 \mathrm{~km}$, which is an important aspect when considering the impacts of mobility.

\subsection{Energy Consumption and GHG Emissions of Passenger Land Transport}

The results in terms of mobility demand can be used to estimate the energy consumption of commuting, as well as the resulting GHG emissions. When comparing the different technologies, a shift from fuels towards electricity tends to decrease the final energy consumption, as electric engines are much more efficient than internal combustion engines (see data in Table 1). In the same way, considering tailpipe emissions only, as is often the case in many regulations, leads to overlooking a significant fraction of the actual impacts. For this reason, the results of this section are focused on WTW emissions, to provide a more comprehensive view on the climate impacts of commuting.

Figure 4 presents the total calculated WTW emissions for a typical working day, with a detail on the different transport modes and fuels that are used. The chart also compares the emissions with the current vehicle stock (as of 2019, left panel) and with the expected vehicle stock in 2030 (right panel). The 2030 vehicle stock also includes a higher share of renewables in power generation, as well as higher shares of biofuels blends in gasoline, diesel and natural gas. The shift to a better vehicle stock alone, including increased efficiency as well as higher penetration of electric vehicles and biofuels blends, allows decreasing the total GHG emissions by $26 \%$, from $19.6 \mathrm{kt} /$ year to $14.5 \mathrm{kt} /$ year. The results highlight the major role of car usage, which represents alone $88 \%$ of the total GHG emissions in both the current and future vehicle stock configurations. At the same time, further emission savings could be obtained by pushing towards additional measures, including remote working and carpooling, as further discussed below. 


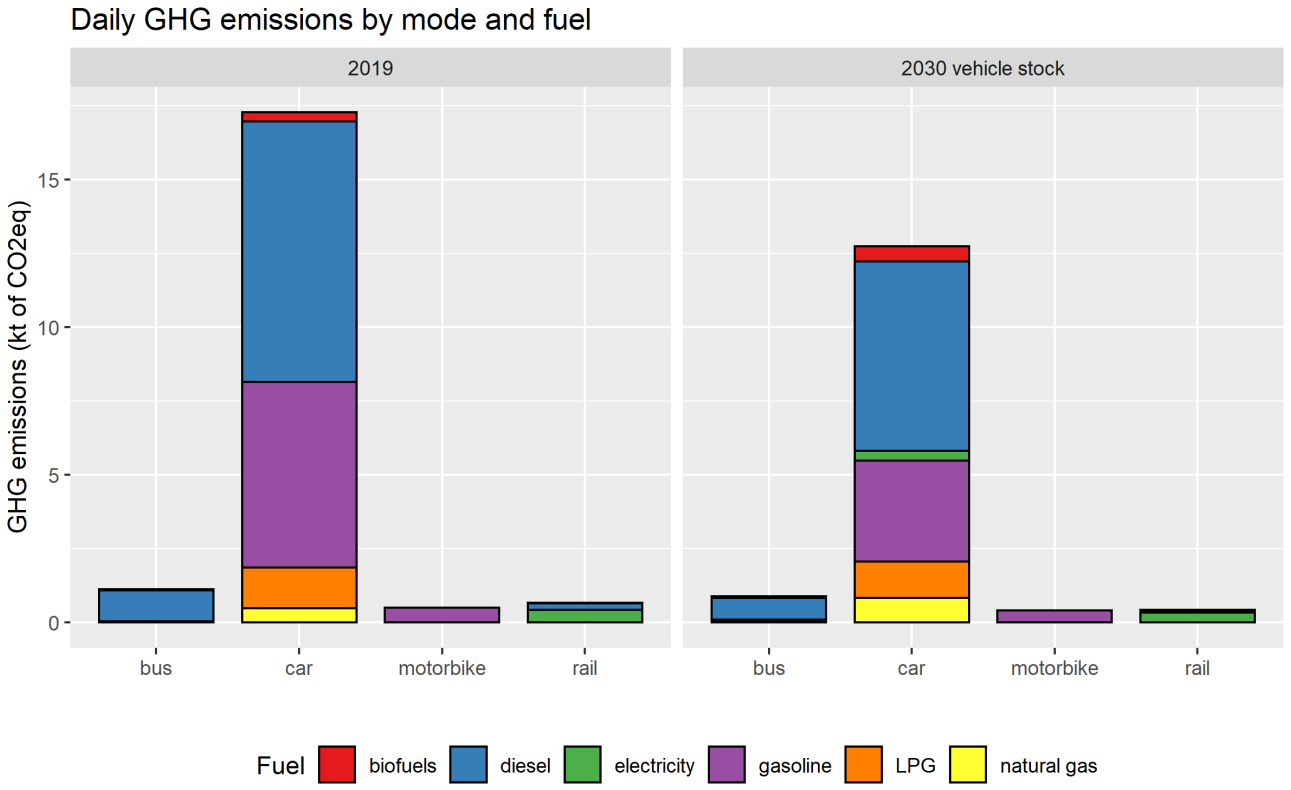

Figure 4. GHG emissions of daily trips by mode in Lombardy, considering a WTW perspective. Emissions by mode and fuel.

Additional information on the shares of GHG emissions by fuel in the different transport modes are presented in Figure 5. The current car stock is based on different fossil fuels, and so are the GHG emissions, with a larger impact of diesel and gasoline. Conversely, bus and motorcycle trips are almost totally relying on diesel and gasoline respectively. Rail emissions (including trains, trams, and subways) are mostly caused by the generation of electricity supplied to those modes, while $~ 30 \%$ of emissions are caused by diesel consumption in non-electrified train lines.

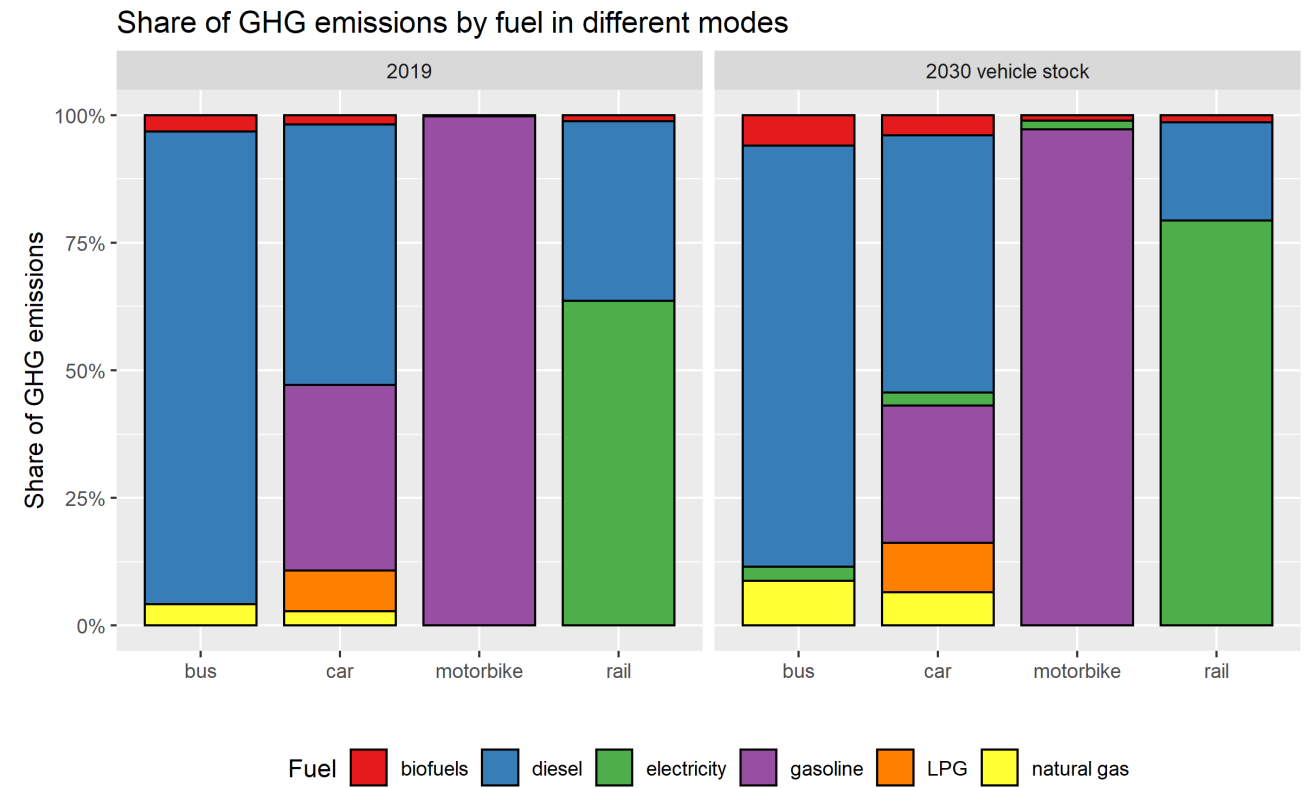

Figure 5. GHG emissions of daily trips by mode in Lombardy, considering a WTW perspective. Share of emissions by fuel in different modes.

All transport modes are seeing a decrease of diesel- and gasoline-related emissions in the future vehicle stock, with an increasing share of alternative fuels, including natural gas, 
biofuels, and electricity. Note that such a shift happens in parallel to an increase of energy efficiency in all vehicles due to technological improvements, as already discussed above.

Finally, when considering distance classes it is clear that the emissions, reported in Figure 6, are mostly in line with the mobility demand discussed in the previous section. The emissions are mostly related to car usage in all distance classes, both with the current and the future vehicle stocks. The share of buses emissions remains comparable across the classes, while the rail (mostly train) emissions share increases with the distance and the motorbike emissions share strongly decreases for trips longer than $25 \mathrm{~km}$.

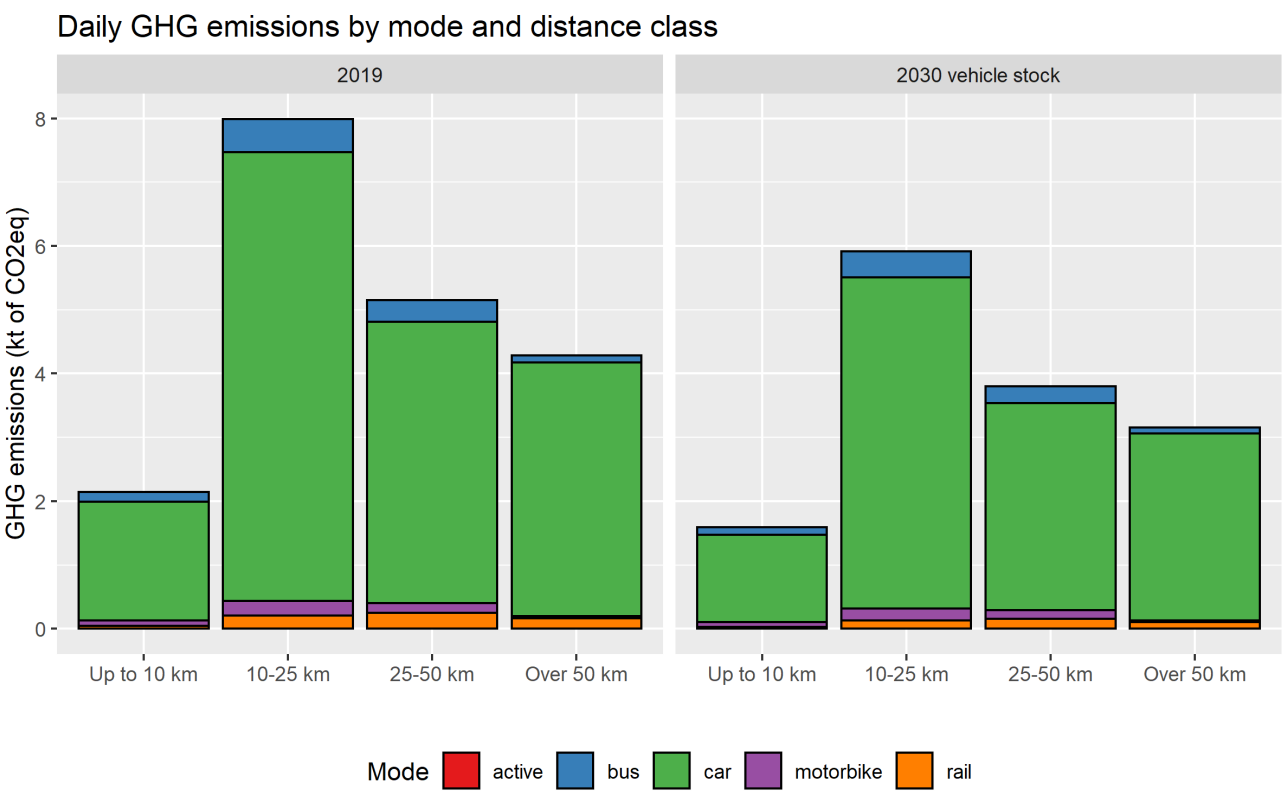

Figure 6. Annual GHG emissions of daily trips in Lombardy, by mode and distance class, considering a WTW perspective.

However, those figures may show significant variations when considering additional trends that will shape the future of commuting, including mobility demand variations as well as policies supporting modal shift and shared mobility. This paper evaluates the potential effects of two specific trends: remote working and carpooling. Another significant trend, which is widely described in the literature, is the modal shift from car usage towards more sustainable modes, including public transport and active modes. While some results presented above about mobility demand highlight the potential of public transport and active modes, a thorough analysis of modal shift, which involves several aspects, is beyond the scope of this work.

\subsection{The Contribution of Remote Working}

The potential contribution of remote working to lower the GHG emissions related to commuting is strongly related to the distribution of this scheme across commuting trips. Figure 7 reports a comparison of the different strategies that have been considered, with a variable share of remote working penetration, up to $10 \%$ of the total trips.

The chart shows that an even distribution of remote workers across the commuting population would lead to a $4 \%$ emission savings when considering a $10 \%$ penetration rate, assuming that remote working is applied for three out of five working days per week. Such decrease is evaluated on total passenger transport emissions, including trips that are done for non-work reasons, and which are of course not affected by remote working (e.g., trips to school, to run errands, etc.). If remote working is limited to people commuting by car, the emission savings increase to $6 \%$, given the average higher impact of car commuting. 


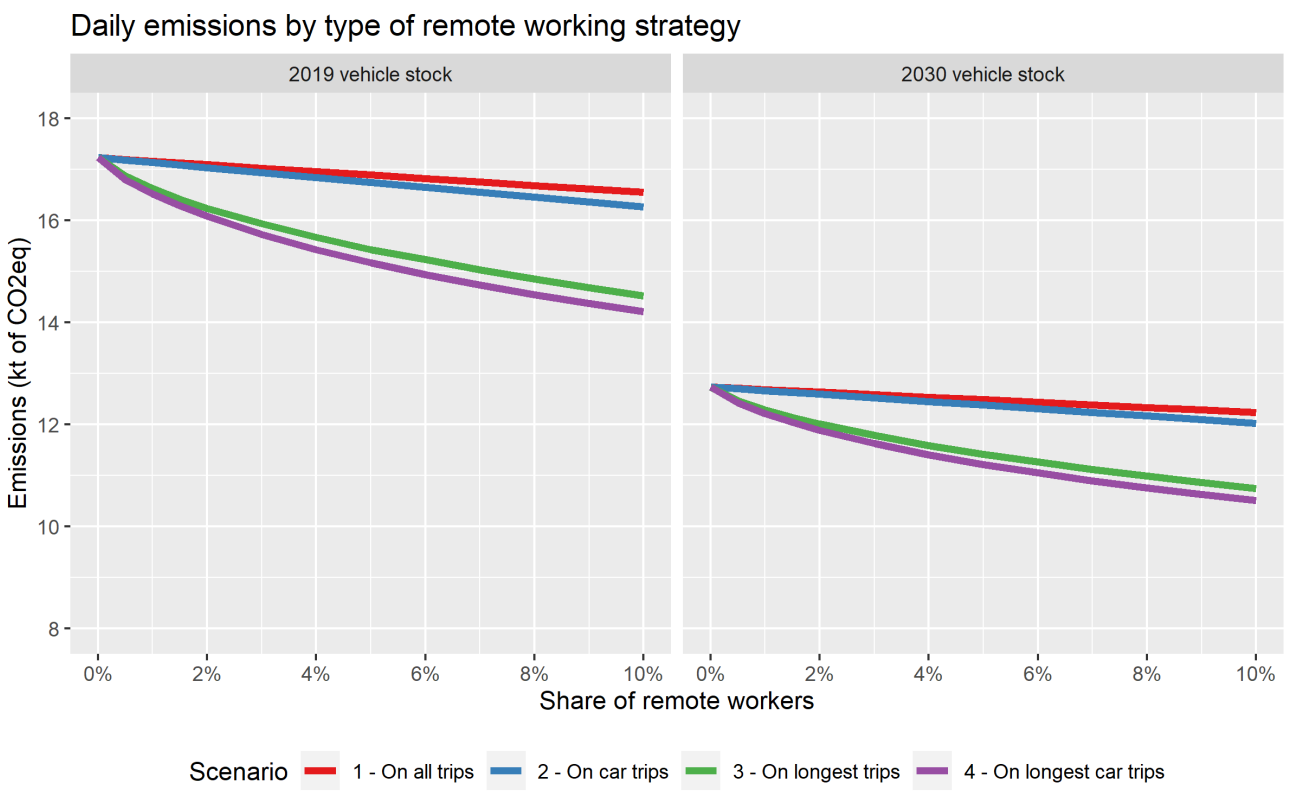

Figure 7. The effect of remote working on daily GHG emissions of passenger trips in Lombardy, by remote working strategy.

Still, much higher emission savings could be achieved by applying remote working to commuters that face the longest daily trips, which are represented in the chart by the third strategy (on total trips) and the fourth strategy (on car trips). If remote working is applied to the $10 \%$ share of commuters with higher trip distances, the benefits could decrease commuting emissions by $16-17 \%$. In absolute terms, those savings represent $2.7-3.0 \mathrm{kt}$ of daily $\mathrm{CO}_{2 \mathrm{eq}}$ emissions considering the 2019 vehicle stock, and 2.0-2.2 kt of dialy $\mathrm{CO}_{2 \mathrm{eq}}$ emissions considering the 2030 vehicle stock.

In these two strategies, the slope of the curves highlights that the marginal benefits decrease with higher penetration rates, due to the fact that commuters are sorted by the distance of the trip, which is directly related to its impact (when considering the same transport mode). Such result is important in terms of policy applicability and effectiveness, as any governance effort for increasing the amount of remote working would bear much more significant results if it were applied non-homogeneously across workers and, specifically, if it were applied based on commuting distance.

These results show the potential contribution of remote working, especially when applied on longer trips. It is important to note that these figures assume that all the commuters could benefit from remote working, while in reality some of them may not be able to do so, either because of the type of their work or for other reasons. Thus, these results, especially for strategies 3 and 4, should be interpreted as maximum potential reductions.

\subsection{The Contribution of Carpooling}

The contribution of carpooling is harder to estimate than for remote working, given the additional limitations that have been discussed in Section 2.3.2. The strongest limit is that carpooling is generally difficult to achieve on long routes, which have often fewer commuters whose origin, destination, and timing are also less likely to match. On the other hand, it is true that the carpooling benefits could be stronger in these cases (higher economic savings, lower stress than driving alone, etc.), but it is difficult to quantify these additional effects.

As previously mentioned, carpooling has been applied to routes with at least 50 people traveling by car for work, to exclude routes for which it may be harder to find suitable matching between different drivers. This choice may slightly underestimate the potential for carpooling in some routes, given the higher incentives to choose this scheme by drivers traveling for longer distances. 
The results presented in Figure 8 show the effect of different carpooling shares in terms of displaced trips and total emissions, compared with the results that have been previously presented on remote working. As a number of routes are excluded, and mostly the longer ones, the carpooling effect appears to be much lower than for remote working. Moreover, as some routes are excluded, the same level of users in both measures leads to different effects in terms of the share of displaced trips. With the proposed assumptions, a carpooling share of $20 \%$ leads to $6.5 \%$ of displaced trips (due to the fact that total trips also include trips unrelated to work commuting).

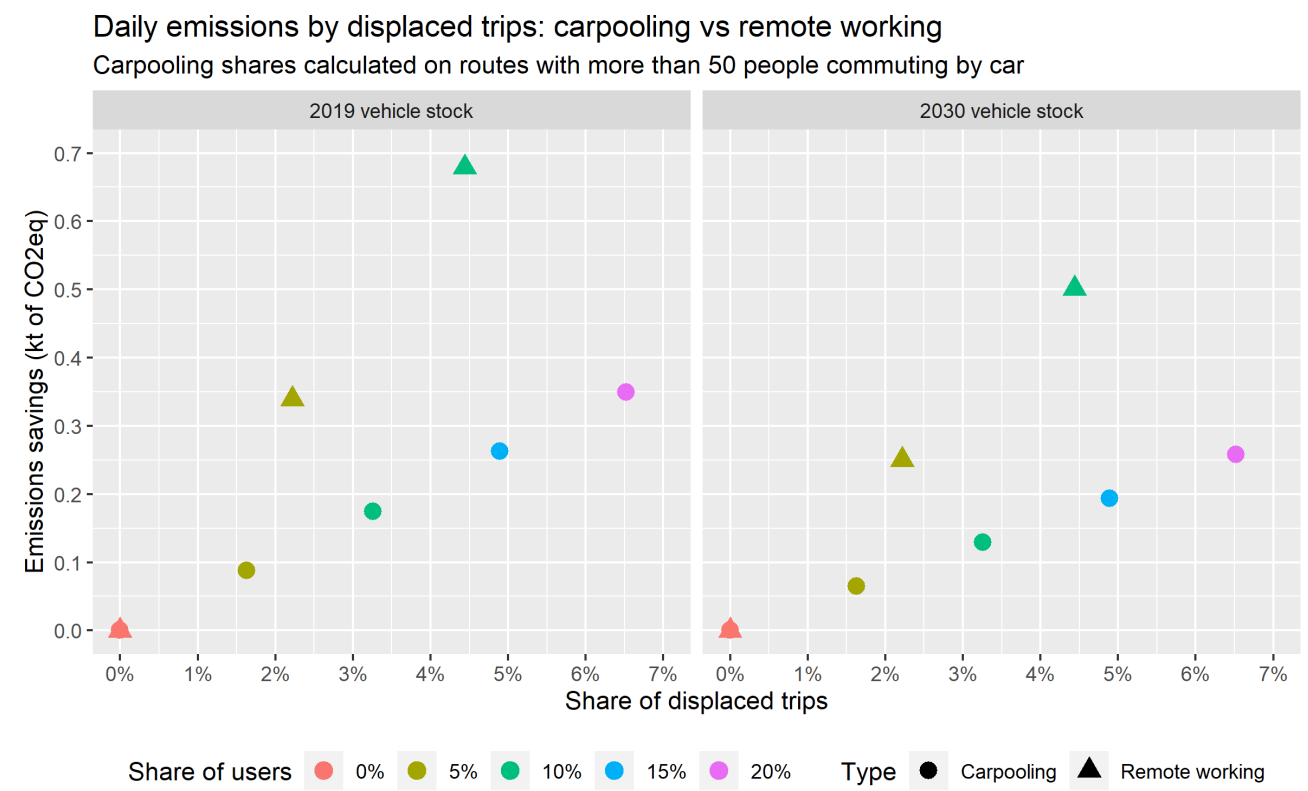

Figure 8. The effect of carpooling on daily GHG emissions of commuting trips in Lombardy, compared with remote working. Carpooling is limited to routes with more than 50 people commuting by car.

In terms of GHG emission savings, the benefits seem to be limited, especially when compared to the remote working results that have been presented above. This is caused by the fact that remote working appears to have a higher potential and lower barriers, at least with the hypotheses considered in this paper, whose limitations will be further addressed in the Section 4 below. The main reason is that longer trips, which have the highest contributions in terms of emissions, usually happen on routes with a low number of car commuters.

The potential impact of the arbitrary threshold of 50 daily car trips has been assessed, to evaluate the effect of this choice. Even by strongly reducing such threshold down to five daily car trips, the results still remain comparable to remote working figures when considering the same number of affected trips.

Still, while in this paper remote working and carpooling have been evaluated separately, these two measures could also be implemented together. From the results of this study remote working seems to be more effective in terms of emissions savings, but the commuters that cannot apply for remote working (e.g., due to the characteristics of their work) could still benefit from carpooling measures. In this sense, the two measures are not to be thought of as competitive but as complimentary, and the subset of workers who cannot work remotely, cannot carpool and travel long distances by car is by definition smaller than any of such subsets taken individually.

\section{Discussion}

The first part of this paper highlights the environmental effect of commuting trips in Lombardy in terms of energy-related GHG emissions. Commuting is just one of the 
main trip motives in the total mobility demand but one of the most significant nonetheless, and thanks to its regularity, some actions can be easier to implement or more effective than for other types of trips. The main focus here has been on remote working and carpooling, but a generalized modal shift from car towards public or active transport is another interesting option (which has not been considered in this study).

When considering GHG emissions, which have been calculated by estimating the energy consumption together with specific emission factors, the largest share is represented by cars. This is of course in line with the fact that car is responsible for the largest modal share in the Italian commuting, but cars also show specific energy consumption per pkm that is higher than for other modes. An important parameter affecting energy performance is the very low occupancy rate of cars in commuting trips, which is often below 1.2 for all trips and even below 1.1 for work trips specifically.

When looking at future estimations, the potential effect of a renewed vehicle stock by 2030 is important, both thanks to an improvement of the technology and to the shift towards low-carbon options, including electric vehicles and biofuels (both liquids and bio-methane, which is gaining importance in Italy). The figures that are used in this paper are based on the most up-to-date national targets, but real figures may change after the COVID-19 pandemic, although concurrent trends are emerging. The economic crisis may slow the vehicle stock renewal, but EU and national decarbonization targets are actually increasing, and this could lead to even higher adoption rates of low-carbon solutions in passenger transport.

The second part of this paper is focused on the potential contribution of remote working and carpooling in decreasing the total energy consumption and GHG emissions of commuting in Lombardy.

Remote working shows an interesting potential, especially if deployed in a selective way by prioritizing the longest trips, with higher effects in terms of emissions. Additional advantages exist, such as the time that is saved by commuters, their higher quality of life, etc. Still, when choosing how to allocate remote working other aspects should be taken into account, including the condition of workers (the care of children or elderly, etc.), the type of job, etc. This work considers only the effect of strategies based on emissions, but it is important to remember that other aspects are at play. In fact, the pandemic is also showing that not all workers may be happy to work remotely. Additionally, dedicated analyses on specific case studies could provide more useful insights, for example, on the evaluation of additional effects such as congestion in cities.

Conversely, the effect of carpooling seems to be harder to scale-up and to contribute significant benefits in terms of emission savings. Still, it might remain an interesting option to be applied to the trips that cannot be displaced by remote working, nor can shift towards public transport solutions. In general, long-distance commuters already prefer public transport when it is available and convenient. However, a proper evaluation of users' behaviour needs to take into account multiple factors, including the cost of each mode, its flexibility, convenience, punctuality, and reliability. Dedicated policies will need to be implemented to support an effective improvement of carpooling in the future, also by creating economic value from its potential benefits in terms of emission savings (e.g., with emissions credits schemes).

While this work provides some interesting insights, it is important to remember that this analysis presents some limitations.

The origin-destination (OD) matrix that has been used as input [29], although very detailed, may show significant differences due to COVID-19 effects. Unfortunately, there still is little data to provide an effective estimation of these impacts, as it is early to understand how COVID-19 may have an effect on both total mobility demand and modal choices in the medium term.

As described in the methodology section, the estimation of trips between different municipalities is reliable, but trips within the same municipality are affected by higher uncertainty. An estimation of the distance has been based on the available data, accuracy 
could and should be improved through enhanced and more detailed data collection in the future.

Moreover, each analysis of transportation impact on a broad scale is usually relying on average energy consumption figures and vehicle stock distributions. The use of average values represents an additional limitation, as specific vehicle categories may be associated to certain behaviors (e.g., longer trips). While we partially addressed this issue by considering weighted shares (see Table 3),in some specific cases this phenomenon could exist. Still, we believe that this effect is marginal in our aggregate results.

Although the most detailed and up-to-date information has been used, uncertainties remain when projecting future values. In particular, the 2030 vehicle stock has been defined based on the most updated targets that are available, but actual figures may prove to be somewhat different in the future [40]. The most important aspects include the average size of future cars (given the rising importance of sport utility vehicles in the last years), the actual rates of EVs deployment as well as the driving habits of users. This discrepancy between projected and actual figures might be particularly significant because, as of this writing, the European Union is discussing its "Fit for 55" package where a strong focus is put on phasing out ICE-vehicles by 2035 [41].

The results that are presented in this work are based on the case of Lombardy, and other regions and countries may show different figures, based on a range of aspects including population density and distribution, employment by sectors, motorization rates, and modal shares. Still, commuting trends show significant similarities in an international context, and the results presented here can be useful for other cases, both in developed and developing countries. In addition, the proposed methodology can be applied to other cases where similar input data are available.

Finally, the values presented in our charts are reported as average values, without a specific analysis on the uncertainty of these results, especially for GHG emissions. Average emissions are estimated based on the most recent emission factors calculated for Europe, with an additional focus on Italy for electricity (as it is the energy carrier most affected by variations at national level). Still, the uncertainty of emission factors has an important impact on the final results, as emission values are subject to error propagation, as demonstrated by recent research $[42,43]$. In particular, electricity emission factors show significant variations over time [44], and for this reason the consumption pattern has an important impact on the effective emissions of any final use, including electric mobility [45]. For this reason, this aspect will gain more importance in the future, with the foreseen rising share of electricity in the total final energy consumption of the transport sector. In addition to electricity, uncertainty on emissions related to other energy carriers [46], especially in the well-to-tank emission factor, due to the different parameters involved in the assessment of their supply chains [47].

For all these reasons, our future research on this topic will include a dedicated analysis on the uncertainty of GHG emissions, in order to assess the confidence intervals of our results.

\section{Conclusions}

This paper presents an analysis of daily commuting in Lombardy, which illustrates the mobility demand and its modal share, and estimates the energy consumption and GHG emissions related to commuting.

Approximately $26.5 \%$ of the 17 million daily trips in Lombardy are related to work commuting, and the daily climate emissions related to land transport in the region are $\sim 17 \mathrm{kt}$ of $\mathrm{CO}_{2 \text { eq. }}$. The evolution of the vehicle stock expected in the next decade, all other things being equal (e.g., total mobility demand, modal share, etc.), can decrease these impacts by $\sim 26 \%$, thanks to efficiency improvements and a gradual shift towards more sustainable technologies (mainly electricity and biofuels).

The results highlight the central role of private cars in daily commuting, representing a significant share of total daily trips, and an even larger share of the total energy consump- 
tion and emissions related to commuting. This is due to the comparatively higher impact of car usage, also as a consequence of the very low occupancy rate in commuting trips, which is $\sim 1.16$ occupants per car. While the distribution of trips for cars and buses is very similar, the higher preference for cars in absolute terms is related to a number of aspects, including acceptable cost, convenience, reliability, and flexibility as well as cultural norms.

This paper also assesses the potential contribution of specific solutions to decrease commuting emissions, focusing on remote working and carpooling. On one hand, the results show that remote working can provide some notable effects, as a $10 \%$ of remote workers (considering on average 3 days per week) could save between $4 \%$ and $17 \%$ of total GHG emissions. The variation is related to how this $10 \%$ is distributed across trips, and the largest potential lies in remote working being promoted among commuters who face the longest distance to travel. On the other hand, carpooling seems to produce limited benefits, due to higher limitations for its implementation that make it hard to displace the same number of trips and even harder if long-distance commuting trips are considered.

Considering the future evolution of commuting, COVID-19 pandemic will have dramatic effects on the past trends, especially on the short- and medium-term. The economic crisis is hitting many sectors at different levels, and remote working is already seeing rising penetration rates that may hold in the future.

The results of this paper are based on very detailed data obtained by different sources, providing a comprehensive picture of the pre-pandemic characteristics of passenger transport in Lombardy. An update of this data is expected in the next few years, and it may provide new figures on recent trends and help to project how the future of commuting may look like.

While the results are based on an Italian region, similar considerations can be extended to other regions and countries. The very same methodology can be replicated for other cases, provided that similar input data is available with the required level of detail.

Author Contributions: Conceptualization: M.N. and M.J.; methodology: M.N. and M.J.; formal analysis: M.N.; data curation: M.N.; writing—original draft preparation: M.N. and M.J.; writingreview and editing: M.N. and M.J. All authors have read and agreed to the published version of the manuscript.

Funding: This research did not receive any specific grant from funding agencies in the public, commercial, or not-for-profit sectors.

Data Availability Statement: The data presented in this study are available on request from the corresponding author.

Conflicts of Interest: The authors declare no conflict of interest.

\begin{tabular}{|c|c|}
\hline \multicolumn{2}{|c|}{ Abbreviations } \\
\hline \multicolumn{2}{|c|}{ The following abbreviations are used in this manuscript: } \\
\hline BEV & battery electric vehicle \\
\hline CNG & compressed natural gas \\
\hline COVID & corona virus disease \\
\hline GHG & greenhouse gas \\
\hline GIS & geographic information system \\
\hline $\mathrm{HEV}$ & hybrid electric vehicle \\
\hline ICE & internal combustion engine \\
\hline LPG & liquefied petroleum gas \\
\hline OD & origin-destination \\
\hline PHEV & plug-in hybrid electric vehicles \\
\hline RES & renewable energy sources \\
\hline TTW & tank-to-wheels \\
\hline WTT & well-to-tank \\
\hline WTW & well-to-wheels \\
\hline
\end{tabular}




\section{References}

1. International Energy Agency. World Energy Outlook 2020; OECD Publishing: Paris, France, 2020.

2. Edelenbosch, O.; van Vuuren, D.; Blok, K.; Calvin, K.; Fujimori, S. Mitigating energy demand sector emissions: The integrated modelling perspective. Appl. Energy 2020, 261, 114347. [CrossRef]

3. Kissinger, M.; Reznik, A. Detailed urban analysis of commute-related GHG emissions to guide urban mitigation measures. Environ. Impact Assess. Rev. 2019, 76, 26-35. [CrossRef]

4. Nematchoua, M.K.; Orosa, J.A.; Reiter, S. Energy consumption assessment due to the mobility of inhabitants and multiannual prospective on the horizon 2030-2050 in one Belgium city. Energy 2019, 171, 523-534. [CrossRef]

5. Wei, P.; Pan, H. Research on individual carbon dioxide emissions of commuting in peri-urban area of metropolitan cities-An empirical study in Shanghai. Transp. Res. Procedia 2017, 25, 3459-3478. [CrossRef]

6. Fenner, A.E.; Kibert, C.J.; Li, J.; Razkenari, M.A.; Hakim, H.; Lu, X.; Kouhirostami, M.; Sam, M. Embodied, operation, and commuting emissions: A case study comparing the carbon hotspots of an educational building. J. Clean. Prod. 2020, $268,122081$. [CrossRef]

7. Virág, D.; Wiedenhofer, D.; Haas, W.; Haberl, H.; Kalt, G.; Krausmann, F. The stock-flow-service nexus of personal mobility in an urban context: Vienna, Austria. Environ. Dev. 2021, 100628. [CrossRef]

8. Lazzeroni, P.; Olivero, S.; Repetto, M.; Stirano, F.; Vallet, M. Optimal battery management for vehicle-to-home and vehicle-to-grid operations in a residential case study. Energy 2019, 175, 704-721. [CrossRef]

9. Zhang, X.; Zou, Y.; Fan, J.; Guo, H. Usage pattern analysis of Beijing private electric vehicles based on real-world data. Energy 2019, 167, 1074-1085. [CrossRef]

10. Bartolini, A.; Comodi, G.; Salvi, D.; Østergaard, P.A. Renewables self-consumption potential in districts with high penetration of electric vehicles. Energy 2020, 213, 118653. [CrossRef]

11. Ioakimidis, C.S.; Thomas, D.; Rycerski, P.; Genikomsakis, K.N. Peak shaving and valley filling of power consumption profile in non-residential buildings using an electric vehicle parking lot. Energy 2018, 148, 148-158. [CrossRef]

12. Fischer, D.; Harbrecht, A.; Surmann, A.; McKenna, R. Electric vehicles' impacts on residential electric local profiles-A stochastic modelling approach considering socio-economic, behavioural and spatial factors. Appl. Energy 2019, 233-234, 644-658. [CrossRef]

13. Falchetta, G.; Noussan, M. Electric vehicle charging network in Europe: An accessibility and deployment trends analysis. Transp. Res. Part D Transp. Environ. 2021, 94, 102813. [CrossRef]

14. Anthopoulos, L.; Kolovou, P. A Multi-Criteria Decision Process for EV Charging Stations' Deployment: Findings from Greece. Energies 2021, 14, 5441. [CrossRef]

15. Nigro, M.; Ferrara, M.; De Vincentis, R.; Liberto, C.; Valenti, G. Data Driven Approaches for Sustainable Development of E-Mobility in Urban Areas. Energies 2021, 14, 3949. [CrossRef]

16. Campaña, M.; Inga, E.; Cárdenas, J. Optimal Sizing of Electric Vehicle Charging Stations Considering Urban Traffic Flow for Smart Cities. Energies 2021, 14, 4933. [CrossRef]

17. Wimbadi, R.W.; Djalante, R.; Mori, A. Urban experiments with public transport for low carbon mobility transitions in cities: A systematic literature review (1990-2020). Sustain. Cities Soc. 2021, 72, 103023. [CrossRef]

18. Acheampong, R.A.; Cugurullo, F.; Gueriau, M.; Dusparic, I. Can autonomous vehicles enable sustainable mobility in future cities? Insights and policy challenges from user preferences over different urban transport options. Cities 2021, 112, 103134. [CrossRef]

19. Hook, A.; Court, V.; Sovacool, B.K.; Sorrell, S. A systematic review of the energy and climate impacts of teleworking. Environ. Res. Lett. 2020, 15, 093003. [CrossRef]

20. Chakrabarti, S. Does telecommuting promote sustainable travel and physical activity? J. Transp. Health 2018, 9, 19-33. [CrossRef]

21. de Abreu e Silva, J.; Melo, P.C. Does home-based telework reduce household total travel? A path analysis using single and two worker British households. J. Transp. Geogr. 2018, 73, 148-162. [CrossRef]

22. Pohl, J.; Hilty, L.M.; Finkbeiner, M. How LCA contributes to the environmental assessment of higher order effects of ICT application: A review of different approaches. J. Clean. Prod. 2019, 219, 698-712. [CrossRef]

23. Shiraki, H.; Matsumoto, K.; Shigetomi, Y.; Ehara, T.; Ochi, Y.; Ogawa, Y. Factors affecting $\mathrm{CO}_{2}$ emissions from private automobiles in Japan: The impact of vehicle occupancy. Appl. Energy 2020, 259, 114196. [CrossRef]

24. Sovacool, B.K.; Griffiths, S. The cultural barriers to a low-carbon future: A review of six mobility and energy transitions across 28 countries. Renew. Sustain. Energy Rev. 2020, 119, 109569. [CrossRef]

25. Monchambert, G. Why do (or don't) people carpool for long distance trips? A discrete choice experiment in France. Transp. Res. Part A Policy Pract. 2020, 132, 911-931. [CrossRef]

26. Jojob. Jojob-Corporate Carpooling in Italy. 2019. Available online: https://https://www.jojob.it/ (accessed on 20 July 2021).

27. Li, R.; Liu, Z.; Zhang, R. Studying the benefits of carpooling in an urban area using automatic vehicle identification data. Transp. Res. Part C Emerg. Technol. 2018, 93, 367-380. [CrossRef]

28. Liu, X.; Yan, X.; Liu, F.; Wang, R.; Leng, Y. A trip-specific model for fuel saving estimation and subsidy policy making of carpooling based on empirical data. Appl. Energy 2019, 240, 295-311. [CrossRef]

29. Regione Lombardia. Matrice OD 2020-Passeggeri. 2019. Available online: https://www.dati.lombardia.it/Mobilit-e-trasporti/ Matrice-OD2020-Passeggeri/hyqr-mpe2 (accessed on 1 July 2021).

30. ISTAT. Matrice Delle Distanze. 2014. Available online: https://www.istat.it/it/archivio/157423 (accessed on 1 July 2021). 
31. Huss, A.; Weingerl, P. JEC Tank-To-Wheels Report v5: Passenger Cars. EUR 30270 EN; Technical Report; Publications Office of the European Union: Luxembourg, 2020. [CrossRef]

32. Prussi, M.; Yugo, M.; De Prada, L.; Padella, M.; Edwards, R. JEC Well-To-Wheels Report v5. EUR 30284 EN; Technical Report; Publications Office of the European Union: Luxembourg, 2020. [CrossRef]

33. Automobile Club Italia. Autoritratto 2019_Parco Veicolare. 2020. Available online: https://www.aci.it/laci/studi-e-ricerche/ dati-e-statistiche/autoritratto/autoritratto-2019.html (accessed on 1 July 2021).

34. Unione Petrolifera. Previsioni di Domanda Energetica e Petrolifera Italiana 2019-2040. 2019. Available online: https://www. unem.it/wp-content/uploads/2019/06/Previsioni-domanda-energetica-e-petrolifera-2019_2040.pdf (accessed on 1 July 2021).

35. Noussan, M.; Tagliapietra, S. The effect of digitalization in the energy consumption of passenger transport: An analysis of future scenarios for Europe. J. Clean. Prod. 2020, 258, 120926. [CrossRef]

36. ISPRA. Fattori di Emissione per la Produzione ed il Consumo di Energia Elettrica in Italia. 2020. Available online: http:/ / www.sinanet.isprambiente.it/it/sia-ispra / serie-storiche-emissioni/fattori-di-emissione-per-la-produzione-ed-ilconsumo-di-energia-elettrica-in-italia/view (accessed on 1 July 2021).

37. Ahern, A.; Weyman, G.; Redelbach, M.; Schulz, A.; Akkermans, L.; Vannacci, L.; Anoyrkati, E.; Van Grinsven, A. Analysis of National Travel Surveys in Europe-OPTIMISM WP2: Harmonisation of National Travel Statistics in Europe; Publications Office of the European Union: Luxembourg, 2013.

38. Carminucci, C.; Procopio, M.; Trepiedi, L. $17^{\circ}$ Rapporto Sulla Mobilità Degli Italiani; Technical Report; ISFORT: Rome, Italy, 2020.

39. Jacobs-Crisioni, C.; Kompil, M.; Baranzelli, C.; Lavalle, C. Indicators of Urban Form and Sustainable Urban Transport; Joint Research Centre, European Commission: Ispra, Italy, 2015; pp. 1-36.

40. Craglia, M.; Cullen, J. Modelling transport emissions in an uncertain future: What actions make a difference? Transp. Res. Part D Transp. Environ. 2020, 89, 102614. [CrossRef]

41. Council of the European Union. Fit for 55-The EU's Plan for a Green Transition; Council of the European Union: Brussels, Belgium, 2021.

42. Lee, K.M.; Lee, M.H.; Lee, J.S.; Lee, J.Y. Uncertainty Analysis of Greenhouse Gas (GHG) Emissions Simulated by the Parametric Monte Carlo Simulation and Nonparametric Bootstrap Method. Energies 2020, 13, 4965. [CrossRef]

43. Lee, K.M.; Lee, M.H. Uncertainty of the Electricity Emission Factor Incorporating the Uncertainty of the Fuel Emission Factors. Energies 2021, 14, 5697. [CrossRef]

44. Kono, J.; Ostermeyer, Y.; Wallbaum, H. The trends of hourly carbon emission factors in Germany and investigation on relevant consumption patterns for its application. Int. J. Life Cycle Assess. 2017, 22, 1493-1501. [CrossRef]

45. Noussan, M.; Neirotti, F. Cross-Country Comparison of Hourly Electricity Mixes for EV Charging Profiles. Energies 2020, 13, 2527. [CrossRef]

46. Wei, F.; Zhang, X.; Chu, J.; Yang, F.; Yuan, Z. Energy and environmental efficiency of China's transportation sectors considering $\mathrm{CO}_{2}$ emission uncertainty. Transp. Res. Part D Transp. Environ. 2021, 97, 102955. [CrossRef]

47. Ozawa, A.; Kudoh, Y. Assessing Uncertainties of Life-Cycle $\mathrm{CO}_{2}$ Emissions Using Hydrogen Energy for Power Generation. Energies 2021, 14, 6943. [CrossRef] 